Egyptian

Orthodontic Journal

\title{
SELLA TURCICA SIZE IN SUBJECTS WITH CLEFTS: LONGITUDINAL CEPHALOMETRIC MEASUREMENTS
}

\author{
Eman A. AlKofide, BDS, MS, FCMDOP, D.Sc.*
}

ABSTRACT

The purpose of this study was to examine the size of sella turcica in cleft subjects from the age of 4-33 years by using standardized serial Cateral radiographic cepholgrams. Forty-nine subjects with cleft of the lip and/or palate were included; 24 unilateral cleft lip and palate (UCLP), 17 bilateral cleft of the lip and palate (BCLP), 6 cleft of the lip $(C L)$, and 2 cleft palate only (CP). The length, depth, and diameter of sella turcica were measured and the mean values were analyzed longitudinally. The results show that when comparing mean dimensional changes of sella turcica between cleft groups, an increase in the diameter of sella turcica was apparent with growth, more so than length and depth. Subjects with VCLP displayed the largest dimensional changes in depth and diameter of sella turcica with age $(+0.04167,+0.04167)$, while subjects with BCLP showed a reduction in the mean length and depth $(-0.05882 \mathrm{~mm},-0.05882 \mathrm{~mm})$. Significant variations were found in the length, depth and diameter of sella turcica between cleft groups $(\mathbb{P}<0.05, \mathbb{P}<0.001$, and $\mathbb{P}<0.001$ respectivefy). When the effect of age was studied, a positive tendency towards an increase in the linear dimensions of dept $h$ and diameter of sella turcica was evident as age increased $(P<0.001)$. We can conclude that the diameter of sella turcica shows the largest change with growth, and that an increase in dimensional change (depth and diameter) in sella turcica occurs in cleft subjects up until the age of 25 years old.

* Associate Professor, Orthodontic Division, King Saud University, College of Dentistry, Riyadh, Saudi Arabia. 
Egyptian

Orthodontic Journal

\section{INTRODUCTION}

It is well known that cleft of the lip and palate is the most common congenital anomaly that affects the craniofacial region. Various genetic and environmental factors have been linked to the formation of clefts. These factors are held responsible for the failure of fusion between the median nasal process and the maxillary process, or between the palatal processes, thus leading to a disturbance in the area of fusion and the formation of clefts. ${ }^{(3,8)}$ The effect of clefts on the development of the craniofacial structures has been an area of concern for many researchers. Clefts have been found to affect the development of the immediate cleft area, the midface region, and can extend to the cranial base region. ${ }^{\left({ }^{6}\right)}$ The influence of these abnormalities on other areas in the cranium such as the sella turcica has not yet been fully investigated. Malformation of the sella turcica has been linked to various genetic disorders and syndromes such as lumbosacral myelmeningocele (spina bifida) ${ }^{(11)}$, trisomy $18 \&$ trisomy $21^{(12,}{ }^{13)}$, holoprosencephaly ${ }^{(10,16)}$, fragile $\mathrm{X}^{(14)}$, solitary median maxillary central incisor ${ }^{(15)}$, and Williams syndrome. ${ }^{(2)}$ In subjects with holoprosencephaly, both the sella turcica region and the pituitary gland within the sella turcica were found to be malformed. ${ }^{(10)}$ Sella turcica morphology was also found to be altered in subjects with Down syndrome. ${ }^{(9,21)}$

With regards to clefts, limited research has been conducted on the sella turcica of individuals affected with this abnormality. In a recent investigation on cleft lip and palate subjects, a high incidence of deviations in sella turcica shape was reported. ${ }^{(18)}$ Research on the size of sella turcica in cleft subjects has also been minimal. In a study conducted by Alkofide (2007), the size of sella turcica was found to be smaller in subjects with clefts compared to subjects without clefts. ${ }^{(1)}$

Sella turcica dimensions have been shown to change from infancy till early adulthood in normal individuals. Thereafter, no significant increase is usually found in sella turcica size. ${ }^{(4)}$ Since the dimensions of sella turcica alter with age, it would be of interest to note if the same pattern occurs in subjects with abnormalities such as clefts.

Therefore, the purpose of this study is to determine the cephalometric measurements of sella turcica in cleft subjects on serial lateral cephalograms, and to analyze the dimensional changes that occur with age.

\section{Materials \& Methods}

This study was performed at the Orthodontic department in the College of Dentistry, King Saud University in Riyadh, Saudi Arabia. The data was derived from serial lateral cephalometric radiographs of non-syndromic individuals with clefts that were taken as part of their treatment planning process. The material comprised of 49

Volume 31 - June 2007 
subjects with cleft of the lip and/or palate; 24 unilateral cleft lip and palate (UCLP), 17 bilateral cleft of the lip and palate (BCLP), 6 cleft of the lip (CL), and 2 cleft palate only (CP). All subjects were Saudi between the ages of 4-33 years old.

\section{Equipment}

The Planmeca PM 2002 CC Proline Cephalostat (Instrumentarium Corp. Imaging Division, Tuusula, Finland) was used to obtain the lateral cephalometric radiographs. These radiographs were taken by trained radiographic technicians in a standardized manner using the same cepholstat. Only radiographs that had the clearest reproduction of the sella turcica area were selected. The midsagittal enlargement was 1.1 fold and all linear measurements were corrected for magnification differences prior to the statistical analyses.

\section{Cephalometric Tracing of sella turcica}

The sella turcica on each cephalometric radiograph was traced on thin acetate paper under optimal illumination by one observer (EK). This tracing was superimposed on graph paper marked in square millimeters to calculate the sella area and measurements were in millimeters to the nearest $0.1 \mathrm{~mm} .^{(22)}$ The configuration of the sella turcica was drawn which consisted of the tuberculum sella, the sella turcica floor, the dorsum sellae, and both anterior and posterior clinoid processes (Figure 1).

\section{Size of sella turcica}

To determine the linear dimensions of sella turcica, the methods of Silverman ${ }^{(22)}$ and Kisling ${ }^{(9)}$ were utilized. All reference lines in the current study were located in the midsagittal plane. The length of the sella turcica was measured as the distance from the tuberculum sella to the tip of the dorsum sellae. The depth of the sella turcica was measured as a perpendicular from the line above, to the deepest point on the floor. A line was also drawn from the tuberculum sella to the furthest point on the posterior inner wall of the fossa. This was considered as the antero-posterior diameter of the sella turcica (Figure 1).

\section{Assessing the errors of the method}

Ten lateral cephalometric radiographs of the cleft subjects were chosen at random and re-traced by the same investigator (EA) 3 weeks apart under identical conditions. Dalhbergs coefficient for assessment of intra-examiner error was used (1940), with the resulting measurements showing good reproducibility of the re-traced radiographs. ${ }^{(5)}$

\section{Statistical Analysis}

Data was analyzed using the Statistical Package for Social Sciences (SPSS) version 14.0 for Windows (SPSS Inc., Chicago, Illinois). ${ }^{(23)}$ Descriptive statistics was 
utilized to analyze the age of the subjects and dimensions of sella turcica, and to report the longitudinal changes in sella turcica linear dimensions. The ANOVA test was used to compare the length, depth, and diameter of sella turcica in cleft subjects, while a regression analysis determined the interrelationship between age and sella turcica linear dimensions (significance was calculated at the 0.05 level).

\section{RESULTS}

Descriptive statistics of the mean age and linear dimensions of sella turcica of all the cleft groups is shown in table 1.

Table 2 displays the changes that were found in the linear dimensions (length, depth, and diameter) of each cleft group measured longitudinally. In the UCLP group, the mean difference in years between measurements in these subjects was 4.5 years, while in the BCLP, the $\mathrm{CL}$, and the $\mathrm{CP}$ the mean year difference was 7.1, 3.2, and 3.5 respectively. When comparing mean changes in length, depth, and diameter between cleft groups, changes in the diameter of sella turcica were more apparent than the other dimensions when examined longitudinally $(+1.33,+1.34,+1.41)$, except in the CP group (it should be taken into account that only $2 \mathrm{CP}$ subjects were present in the study). Changes only in the diameter of sella turcica of the CL subjects were apparent with growth $(+1.41 \mathrm{~mm})$, while BCLP subjects showed negative changes where the mean length and depth became smaller after several years $(-0.05882 \mathrm{~mm},-0.05882 \mathrm{~mm})$. Subjects with UCLP displayed the largest changes in mean length and depth $(+0.04167,+0.04167)$.

When comparing mean measurements of the sella turcica dimensions, subjects with UCLP displayed the smallest measurements in all 3 linear dimensions (length $=9.52$, depth $=8.06$, diameter $=11.62$ ), followed by the BCLP group (Table 2).

Table 3 further illustrates the differences that were found between the linear dimensions of the cleft groups. Significant variations could be seen between the length $(P<0.05)$ depth $(P<0.001)$ and diameter $(P<0.001)$ of sella turcica and the cleft groups.

Table 4 shows the effect of age on the length, depth, and diameter of sella turcica. It can be seen that there is a positive tendency towards an increase in the linear dimensions of sella turcica as age increases. This is apparent while observing the depth and diameter of sella turcica $(P<0.001)$. Figure 2 also illustrates the changes in the linear dimensions of sella turcica as age increases. It can be evident that the depth and diameter of sella turcica in cleft subjects increase up until 25 years of age (51.02\% and 51.02\% respectively). 
Table 1:Descriptive Statistics for all cleft groups

\begin{tabular}{lccc}
\hline & Mean & Std. deviation & N \\
\hline Age & 15.41 & 5.683 & 49 \\
Length & 10.16 & 2.301 & 49 \\
Depth & 8.47 & 2.033 & 49 \\
Diameter & 12.32 & 2.210 & 49 \\
\hline
\end{tabular}

Table 2: Longitudinal changes in sella turcica linear dimensions in each cleft group

\begin{tabular}{cccccccccccccc}
\hline & & \multicolumn{2}{c}{ Years } & \multicolumn{3}{c}{ Length $(\mathbf{m m})$} & \multicolumn{2}{c}{ Depth $(\mathbf{m m})$} & \multicolumn{3}{c}{ Diameter $(\mathbf{m m})$} \\
\cline { 2 - 14 } Groups & $\mathbf{N}$ & $\begin{array}{c}\text { Mean } \\
\text { change }\end{array}$ & $\begin{array}{c}\text { Std. } \\
\text { Dev. }\end{array}$ & $\begin{array}{c}\text { Mean } \\
\text { change }\end{array}$ & $\begin{array}{c}\text { Std. } \\
\text { Dev. }\end{array}$ & Mean & $\begin{array}{c}\text { Mean } \\
\text { change }\end{array}$ & $\begin{array}{c}\text { Std. } \\
\text { Dev. }\end{array}$ & Mean & $\begin{array}{c}\text { Mean } \\
\text { change }\end{array}$ & $\begin{array}{c}\text { Std. } \\
\text { Dev. }\end{array}$ & Mean \\
\hline UCLP & 24 & 4.46 & 2.45 & 0.042 & 1.33 & 9.52 & 0.042 & 1.33 & 8.06 & 1.33 & 1.27 & 11.62 \\
\hline BCLP & 17 & 7.06 & 3.72 & -0.059 & 1.34 & 10.80 & -0.059 & 1.34 & 8.96 & 1.34 & 1.31 & 12.86 \\
\hline CL & 6 & 3.17 & 1.47 & 0.00 & 1.41 & 10.60 & 0.00 & 1.41 & 9.00 & 1.41 & 0.89 & 13.80 \\
\hline CP & 2 & 3.50 & 0.71 & 0.00 & 0.00 & 9.60 & 0.00 & 0.00 & 6.40 & 0.00 & 1.41 & 10.60 \\
\hline
\end{tabular}

Table 3: Analysis of Variance; length, depth, and diameter by cleft groups



$* \mathrm{P}<0.05$

$* * \mathrm{P}<0.001$

Volume 31 - June 2007 
Egyptian

Orthodontic Journal

Table 4: Regression analysis for age and sella turcica linear dimensions

\begin{tabular}{lcccc}
\hline \multirow{2}{*}{ Dimensions } & \multicolumn{5}{c}{ Age } \\
\cline { 2 - 5 } Length & 0.061463 & Std. Error & Sig. & R Square \\
\hline Depth & 0.098336 & 0.0293185 & 0.0744 & 0.02305 \\
\hline Diameter & 0.107671 & 0.031924 & $* *$ & 0.07554 \\
\hline
\end{tabular}

$* * \mathrm{P}<0.001$



Figure 1: Normal sella turcica morphology and reference lines used for measuring sella size; TS=tuberculum sella, DS=dorsum sella, BPF=base of pituitary fossa. Reference line; black line=length of sella, dashed line=diameter of sella, dotted line=depth of sella.

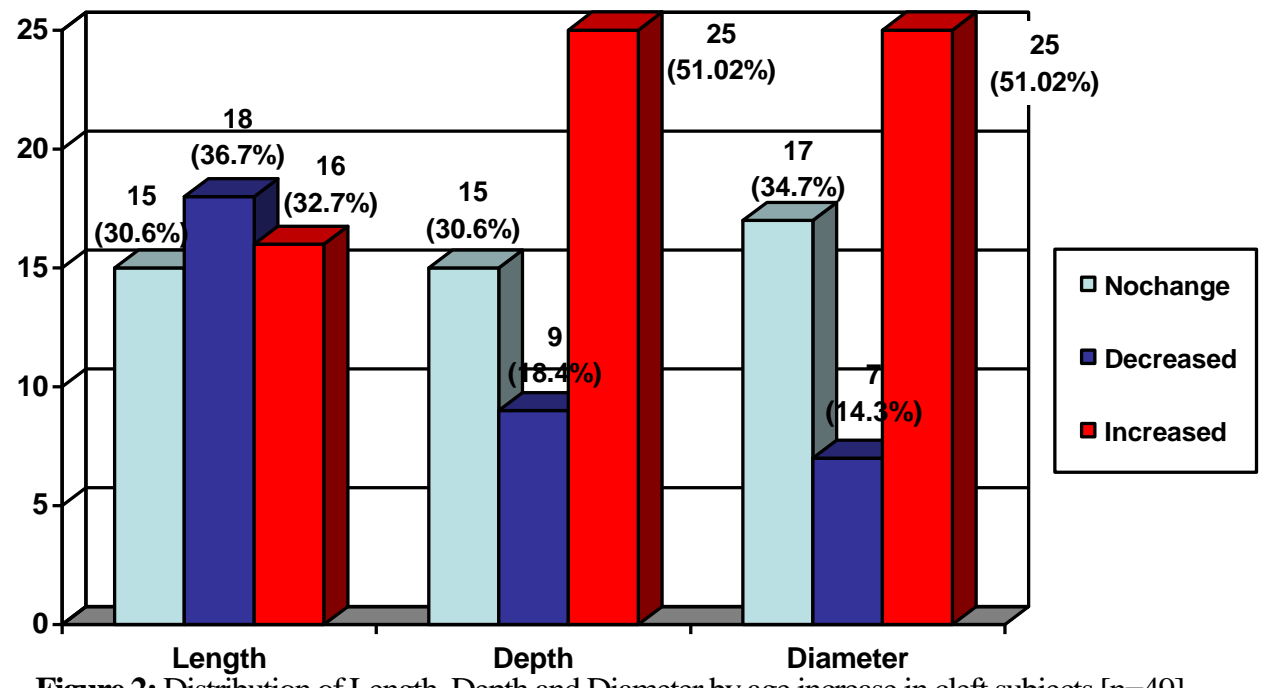

Figure 2: Distribution of Length, Depth and Diameter by age increase in cleft subjects [ $n=49$ ]

Volume 31 - June 2007 
Egyptian

Orthodontic Journal

\section{DISCUSSION}

This study investigates the longitudinal dimensional changes that occur in sella turcica of subjects with clefts with the use of serial lateral cephalometric radiographs. Research of this type on cleft subjects does not seem to have been reported previously. The results of the current study therefore cannot be compared with other studies on cleft subjects but will be related to findings of normal samples.

When evaluating the mean changes in the linear dimensions of sella turcica in each cleft group, differences in the diameter of sella turcica were more evident. An apparent increase occurred in the diameter of sella turcica as the subject aged, more so than length or depth. This is in agreement with Choi et al whom reported that sella turcica diameter had a more proportional increase than depth and length in normal subjects as growth proceeded. ${ }^{(4)}$ When subjects with BCLP were studied in the present study, a reduction in the mean length and depth was apparent compared with the other cleft groups, while subjects with UCLP displayed the largest increase in mean length and depth associated with growth. When the linear dimensions were compared between the cleft groups, significant variations were found in the length, depth, and diameter of sella turcica, where subjects with UCLP showed smaller dimensions when compared with the other cleft groups.

Prior longitudinal studies of the sella turcica agree that growth decreases rapidly after the first years of life, followed by an increase at the time of puberty and a slowing down and ceasing in the late teens or early adulthood. $(17,22)$ Silverman (1956) examined lateral cephalometric radiographs of 320 children from 1 month to 18 years of age to determine the mean values for the area of the sella turcica according to gender and age. His findings were similar with regards to the rapid increase in sella turcica area during the first year of life, with a gradual deceleration in growth rate afterwards. He also noted that acceleration in sella turcica size occurs at the time of puberty between the ages of 11 and 15 years, which may even persist longer in males. ${ }^{(22)}$

Preston (1979) evaluated 182 lateral radiographs of normal individuals aged 5-17 years, and stated that a close correlation between the area of sella and age can be found. He also noted that as age increases, the size of the pituitary fossa increased. ${ }^{(19)}$ Choi et al (2001) conducted a study on 200 orthodontic patients with an age range of 6-24 years old. Subjects were divided into 5 groups by age, and the dimensional changes of sella turcica were examined accordingly. Their results reveal that there was a positive linear tendency in sella turcica 
length, depth, and diameter up until 25 years of age (it is noteworthy to point that in Choi et al study, different terminology for linear dimensions were used). After 26 years, no significant increase was found in sella turcica dimensions. ${ }^{(4)}$ The findings of the current study reveal similar results with prior research where a positive increase in the linear dimensions of sella turcica, especially depth and diameter, occurs up until the age of 25 years old in cleft subjects.

Israel (1970) on the other hand, conducted a study on adults with a minimum age of 24 years, to determine if growth in sella turcica size continued throughout adulthood until later in life. He concluded that there was an increase in the area of sella turcica as the individual ages, which may even persist up until the $7^{\text {th }}$ decade of life. ${ }^{(7)}$ Contrary to Israel, Rasmussen in his study on the human pituitary body determined that hypophyseal weight diminishes from the third decade onwards, with an eventual termination of growth in the sella turcica area as the subject aged. ${ }^{(20)}$

The results of the current study support the notion that the dimensions of sella turcica increase in cleft individuals as they grow until 25 years of age. Whether this increase is at the same rate as normal individuals is a question that needs further research with a larger sample size and the incorporation of a normal sample for comparison purposes.

\section{Conclusion}

We can conclude the following:

- The diameter of sella turcica shows larger changes with growth compared with length and depth.

- Subjects with UCLP display larger mean dimensional changes in depth and diameter of sella turcica with age, while subjects with BCLP show a reduction in mean length and depth.

- A positive tendency towards an increase in the linear dimensions (depth and diameter) of sella turcica is evident as age progresses until 25 years of age.

\section{REFERENCES}

1. Alkofide E. Sella Turcica Morphology and Dimensions in Cleft Subjects. Cleft Palate Craniofacial Journal, 2007. In press.

2. Axelsson S, Storhaug K, Kjaer I. Post-natal size and morphology of the sella turcica in Williams syndrome. European Journal of Orthodontics. 26:613-621, 2004. 
3. Berkowitz S. State of the art in cleft palate orofacial growth and dentistry. A historical perspective. Am J Orthod. 74:564, 1978.

4. Choi WJ, Hwang EH, Lee SR. The study of shape and size of normal sella turcica in cephalometric radiographs. Korean Journal of Oral Maxillofacial Radiology. 31:43-49, 2001.

5. Dahlberg G. Statistical methods for medical and biological students. George Allen and Unwin, London. 1940.

6. Horswell BB, Gallup B V. Cranial base morphology in cleft lip and palate: a cephalometric study from 7 to 18 years of age. Journal of Oral and Maxillofacial Surgery. 50:681-685, 1992.

7. Israel $\mathrm{H}$. Continuing growth in sella turcica with age. American Journal of Roentgenology \& Radium Therapy and Nuclear Medicine. 108:516-527, 1970.

8. Kernahen DA, Rosenstein SW. Cleft lip and palate: a systematic management. $1^{\text {st }}$ edition, 3-51. Williams and Wilkins; Baltimore, 1990.

9. Kisling E. Cranial morphology in Down's syndrome. A comparative roentgencephalometric study in adult males. Munksgaard, Copenhagen, Dissertation, 1966.

10. Kjaer I, Fischer-Hansen B. Human fetal pituitary gland in holprosencephaly and anencephaly. Journal of Craniofacial Genetics and Developmental Biology. 15:222-229, 1995.

11. Kjaer I, Wagner, Madsen $P$, Blichfeldt $S$, Ramussen K, Russell B. The sella turcica in children with lumbosacral myelomeningocele. European Journal of Orthodontics. 20:443-448, 1998a.

12. Kjaer I, Keeling JW, Reintoft I, Hjallgrim H, Nolting D, Fischer-Hansen B. Pituitary gland and sella turcica in human trisomy 18 fetuses. American Journal of Medical Genetics. 76:87-92, 1998b.

13. Kjaer I, Keeling JW, Reintoft I, Nolting D, Fischer-Hansen B. Pituitary gland and sella turcica in human trisomy 21 fetuses related to axial skeletal development. American Journal of Medical Genetics. 80:494-500, 1998c.

14. Kjaer I, Hjalgrim $H$, Russell BG. Cranial and hand skeleton in fragile $X$ syndrome. American Journal of Medical Genetics. 100:156-161, $2001 \mathrm{a}$.

15. Kjaer I, Becktor KB, Lisson J, Gormsen C, Russell BG. Face, palate, and craniofacial morphology in patients with a solitary median maxillary central incisor. European Journal of Orthodontics. 23:63-73, $2001 \mathrm{~b}$. 
16. Kjaer I, Keeling JW, Fischer-Hansen B, Becktor KB. Midline skeletodental morphology in holoprosencephaly. Cleft Palate Craniofacial Journal. 39:357-363, 2002.

17. Melsen B. The cranial base. The postnatal development of the cranial base studied historically on human autopsy material. Acta Odontologica Scandinavica. 32 (Supplement 62): 57-71, 1974.

18. Nielsen BW, Molsted K, Kjaer I. Maxillary and sella turcica morphology in newborns with cleft lip and palate. Cleft Palate Craniofacial Journal. 42:610$617,2005$.

19. Preston CB. Pituitary fossa size and facial type. American Journal of Orthodontists and Dentofacial Orthopedics. 75:259-263, 1979.

20. Rasmussen AT. Quantitative study of human hypophysis cerebri or pituitary body. Endocrinology. 8:509-524, 1924.

21. Russell BG, Kjaer I. Postnatal structure of the sella turcica in Down syndrome. American Journal of Medical Genetics. 87:183-188, 1999.

22. Silverman FN. Roentgen standards for size of the pituitary fossa from infancy through adolescence. American Journal of Roentgenology. 78:451460, 1957.

23. SPSS, Statistical Package for Social Science, Version 10, SPSS Inc, USA, 1999. 